\title{
REVIEW
}

\section{The role of exercise training in chronic heart failure}

\author{
Robert P Wielenga, Andrew J S Coats, Willem L Mosterd, Inge A Huisveld
}

\author{
Department of \\ Cardiology, Ignatius \\ Hospital, Breda, The \\ Netherlands \\ R P Wielenga \\ Royal Brompton \\ Hospital, London SW3, \\ UK \\ A J S Coats \\ Department of \\ Medical Physiology \\ and Sports Medicine, \\ Utrecht University, \\ Utrecht, The \\ Netherlands \\ I A Huisveld \\ W L Mosterd \\ Correspondence to: \\ Dr Wielenga, Department of \\ Medical Physiology and \\ Sports Medicine, \\ Universiteitsweg 100, PO \\ Box 80043, $3508 \mathrm{TA}$ \\ Utrecht, the Netherlands. \\ Accepted for publication \\ 2 July 1997
}

Table 1 Summary of trials of exercise training in patients with chronic heart failure

\begin{tabular}{|c|c|c|c|c|c|c|}
\hline & Year & $n$ & Age & $L V E F$ & Peak $\dot{V}_{2}$ & Study design \\
\hline \multicolumn{7}{|l|}{ Uncontrolled } \\
\hline Sullivan $^{5}$ & 1988 & 12 & $54.0(10.0)$ & $24.0(10.0)$ & $16.8(3.8)$ & Open, no control \\
\hline Minotti $^{6}$ & 1990 & 5 & $60.0(9.0)$ & $27.0(7.6)$ & $15.5(4.5)$ & Open, no control \\
\hline Mancini $^{7}$ & 1995 & 14 & $55.0(14.0)$ & $22.0(9.0)$ & $13.5(4.8)$ & $\begin{array}{l}\text { Unblinded, uncontrolled, } \\
\text { control by drop out }\end{array}$ \\
\hline Hornig $^{8}$ & 1996 & 11 & $47.0(5.0)$ & $21.0(2.0)$ & $17.0(2.0)$ & Open, control by normals \\
\hline Magnusson $^{9}$ & 1996 & 11 & $56.0(9.0)$ & $19.8(11.3)$ & $15.1(2.9)$ & Open \\
\hline \multicolumn{7}{|l|}{ Controlled } \\
\hline Meyer $^{10}$ & 1991 & 12 & $63.0(2.6)$ & $23.0(3.2)$ & $13.0(0.8)$ & $\begin{array}{l}\text { Plecebo controlled } \\
\text { crossover; } \\
\text { lisinopril/placebo } \\
\text { with/without training }\end{array}$ \\
\hline Coats $^{1112}$ & 1992 & 17 & $61.8(1.5)$ & $19.6(2.3)$ & $13.2(0.9)$ & Controlled crossover \\
\hline Davey $^{13}$ & 1992 & 22 & $64 \quad(54-74)$ & $22.0(8.0)$ & $14.1(2.8)$ & Controlled crossover \\
\hline $\mathrm{Koch}^{14}$ & 1992 & 25 & $55.0(10.0)$ & $26.0(10.0)$ & $18.9(7.0)$ & Controlled open \\
\hline Adamopoulos ${ }^{1}$ & ${ }^{5} 1993$ & 12 & $62.4(2.6)$ & $24.0(3.4)$ & $12.1(1.2)$ & Controlled crossover \\
\hline Belardinelli $^{16}$ & 1995 & 55 & $55.0(7.0)$ & $27.0(7.0)$ & $15.6(1.3)$ & Controlled \\
\hline Piepoli $^{17}$ & 1996 & 12 & $59.6(1.7)$ & $26.4(1.6)$ & $14.6(1.4)$ & Controlled crossover \\
\hline
\end{tabular}

Values are mean (SD).

LVEF, left ventricular ejection fraction; peak $\dot{\mathrm{V}}_{2}$, peak oxygen uptake. on physical conditioning in patients with ventricular dysfunction have shown that selected patients can safely undergo exercise training, resulting in an improvement in functional class. $^{23}$

Poor left ventricular function is not necessarily synonymous with chronic heart failure, which is characterised by reduced tissue oxygen supply. The best method of evaluating the disease state of a patient with a compromised heart is cardiopulmonary exercise testing, that is, the measurement of oxygen consumption $\left(\dot{\mathrm{VO}}_{2}\right.$ in $\left.\mathrm{ml} / \mathrm{kg} / \mathrm{min}\right)$ during exercise. In recent years studies on chronic heart failure have therefore focused on the combination of left ventricular dysfunction and a low peak oxygen consumption (less than $20 \mathrm{ml} / \mathrm{kg}$ / min). Determination of aerobic capacity is necessary to allow proper selection of patients for heart failure studies. ${ }^{4}$ In this review we shall focus on the training studies (table 1) performed with chronic heart failure patients in functional class II and III according to the New York Heart Association (NYHA), with a peak oxygen consumption less than $20 \mathrm{ml} / \mathrm{kg} / \mathrm{min}$.

Evaluation of training studies is often hampered by the heterogeneity of exercise programmes and the variation in end points. Moreover, studies generally involve small numbers of patients and frequently a control group is lacking. remaining functional capacity. Several studies

\section{Training programmes}

The training programmes described are diverse, but can be classified according to frequency and duration of active training, and to intensity and mode of training (table 2).

In the majority of the studies, endurance cycle ergometer training ${ }^{511-131516}$ or interval type of training ${ }^{18}$ is employed to improve overall aerobic capacity. Others preferred strength training of local muscle groups, ${ }^{671417}$ sometimes in combination with local endurance training, ${ }^{9}$ to increase strength and aerobic metabolism of skeletal muscle. One programme compared endurance cycle ergometer training with angiotensin converting enzyme (ACE) inhibition. ${ }^{10}$

\section{End points of exercise training as an} intervention in chronic heart failure The effects of the training programmes may be assessed in terms of morbidity, mortality, symptoms, quality of life, or functional capacity. Important end points that have been studied (table 3) include cardiac function and central haemodynamics, ${ }^{51416}$ the sympathetic nervous system, ${ }^{12}$ the peripheral circulation, ${ }^{8}{ }^{17}$ skeletal 
Table 2 Training programme

\begin{tabular}{|c|c|c|c|c|}
\hline & Duration & Frequency & Duration of exercise & Intensity and mode \\
\hline \multicolumn{5}{|l|}{ Uncontrolled } \\
\hline Sullivan $^{5}$ & 4-6 months & 3-5 days/week & $4 \mathrm{~h} /$ week & Submaximal endurance \\
\hline Minotti $^{6}$ & 4 weeks & 6 days/week & $\begin{array}{l}3 \times 8 \text { min exercise, separated by } \\
5 \text { min rest }\end{array}$ & Local strength \\
\hline Mancini $^{7}$ & 12 weeks & 3 days/week & $90 \mathrm{~min}$ & Local strength \\
\hline Hornig $^{8}$ & 4 weeks & Daily & $30 \mathrm{~min}$ & Local strength \\
\hline Magnusson $^{9}$ & 8 weeks & 3 days/week & $45 \mathrm{~min}$ & Local strength, local endurance \\
\hline \multicolumn{5}{|l|}{ Controlled } \\
\hline Meyer $^{10}$ & 6 weeks & 5 days/week & $\begin{array}{l}\text { Week 1-3: } 20 \mathrm{~min} / \text { day Week 4-6: } \\
25 \mathrm{~min} / \text { day }\end{array}$ & Submaximal endurance \\
\hline Coats $^{1112}$ & 8 weeks & 5 days/week & $20 \mathrm{~min}$ & Submaximal endurance \\
\hline Davey $^{13}$ & 8 weeks & 5 days/week & $20 \mathrm{~min}$ & Submaximal endurance \\
\hline $\operatorname{Koch}^{14}$ & 13 weeks & 40 sessions in 90 days & $90 \mathrm{~min}$ & Local strength \\
\hline Adamopoulos ${ }^{15}$ & 8 weeks & 5 days/week & $20 \mathrm{~min}$ & Submaximal endurance \\
\hline Belardinelli ${ }^{16}$ & 8 weeks & 3 days/week & $60 \mathrm{~min}$ & Submaximal endurance \\
\hline Piepoli $^{17}$ & 6 weeks & $2-3$ times/day & $\begin{array}{l}2 \times 5 \text { min exercise, separated by } \\
5 \text { min rest }\end{array}$ & Local strength \\
\hline
\end{tabular}

muscle metabolism, ${ }^{567914}$ arrhythmias, ${ }^{11}{ }^{12}$ respiratory function, ${ }^{11-13} 171^{19}$ and exercise capacity. 511121416

Improvements in exercise capacity or other end points are not necessarily associated with increased survival, and vice versa. It remains to be decided which end point is the most relevant for the assessment of optimal training results.

\section{Effects of training in chronic heart failure patients}

CENTRAL HAEMODYNAMICS AND LEFT

VENTRICULAR FUNCTION

Although the failing heart is considered to be primarily responsible for the syndrome of chronic heart failure, there is a clear discrepancy between exertional symptoms and circulatory function in patients with heart failure. ${ }^{20}$ This has to be taken into account when effects of training on cardiac function are assessed (table 4).

Endurance and local strength training programmes showed little or no effect on left ventricular function in heart failure patients. ${ }^{5914}$ Left ventricular ejection fraction and fractional shortening, as well as central haemodynamics (right atrial, pulmonary capillary wedge, and pulmonary artery pressure) remained unchanged after training. Stroke volume was unchanged at rest, but tended to increase during exercise. ${ }^{5}$ In contrast, Belardinelli et $a l^{16}$ showed an improvement in diastolic function in a subpopulation of patients with dilated cardiomyopathy after an endurance training period of eight weeks, resulting in an increase in exercise time. Coats $e t a l^{12}$ reported favourable effects of endurance training on cardiac output at submaximal and peak exercise.

Finally, rate-pressure product at submaximal exercise, which roughly reflects myocardial oxygen requirement, has been found to be lower after training, indicating more efficient exercise performance. ${ }^{11}$ Endurance training can improve central haemodynamic status, but this is not always associated with an improvement in exercise capacity.

\section{SYMPATHETIC NERVOUS SYSTEM}

Chronic heart failure is accompanied by activation of the autonomic nervous system. An increase in sympathetic tone has been implicated in the accompanying impairment of ventricular function.

Coats et $a l^{12}$ studied the effect of endurance training on autonomic tone, using heart rate variability, autoregressive power spectral analysis of the electrocardiogram, and whole body radiolabelled noradrenaline spillover in 17 patients with chronic heart failure. Each method produced a decrease in sympathetic activity and a concomitant increase in vagal activity. This may improve prognosis by reducing the incidence of sudden death; however, the use of these methods in the evaluation of

Table 3 End points of trials of exercise training

\begin{tabular}{|c|c|c|c|c|c|c|c|c|c|}
\hline & Symptoms & $\begin{array}{l}\text { Morbidity } \\
\text { and } \\
\text { mortality }\end{array}$ & $\begin{array}{l}\text { Ventricular } \\
\text { function, } \\
\text { haemodynamics }\end{array}$ & $C P X$ & Neurohormonal & $\begin{array}{l}\text { Peripheral } \\
\text { circulation }\end{array}$ & $\begin{array}{l}\text { Skeletal } \\
\text { muscle }\end{array}$ & Arrhythmias & $\begin{array}{l}\text { Respiratory } \\
\text { function }\end{array}$ \\
\hline \multicolumn{10}{|l|}{ Uncontrolled } \\
\hline Sullivan $^{5}$ & + & & + & + & & + & + & & \\
\hline Sullivan $^{19}$ & & & & & & & & & + \\
\hline Minotti $^{6}$ & & & & & & & + & & \\
\hline Mancini $^{7}$ & + & & & + & & & $\begin{array}{l}\text { Resp } \\
\text { muscle }\end{array}$ & & + \\
\hline Hornig $^{8}$ & & & & & & + & & & \\
\hline Magnusson $^{9}$ & & & + & + & & & + & & \\
\hline \multicolumn{10}{|l|}{ Controlled } \\
\hline Meyer $^{10}$ & & & & + & & & & & \\
\hline Coats $^{1112}$ & + & & & + & + & + & & + & + \\
\hline Davey $^{13}$ & & & & & & & & & + \\
\hline Koch $^{14}$ & + & & + & + & & & + & & \\
\hline Adamopoulos ${ }^{15}$ & & & & & & & + & & \\
\hline Belardinelli ${ }^{16}$ & + & + & + & + & & & & & \\
\hline Piepoli $^{17}$ & & & + & + & & + & + & & + \\
\hline
\end{tabular}

CPX, Cardiopulmonary exercise testing. 
Table 4 Effects of exercise training on cardiac output (CO) and heart rate (HR)

\begin{tabular}{|c|c|c|c|c|c|}
\hline & $\begin{array}{l}\text { CO } \\
\text { submaximal }\end{array}$ & CO maximal & $H R$ rest & HR submaximal & HR maximal \\
\hline $\begin{array}{l}\text { Uncontrolled } \\
\text { Sullivan }^{519}\end{array}$ & $=$ & $\uparrow(\mathrm{NS})$ & $\downarrow$ & $\downarrow$ & $=$ \\
\hline $\begin{array}{l}\text { Controlled } \\
\text { Coats }^{11} \\
\text { Coats }^{12} \\
\text { Meyer }^{10}\end{array}$ & $\uparrow$ & $\uparrow(\mathrm{p}<0.05)$ & $\begin{array}{l}\downarrow \\
\downarrow \\
=\end{array}$ & $\begin{array}{l}\downarrow \\
\downarrow \\
=\end{array}$ & $\begin{array}{l}= \\
=\end{array}$ \\
\hline
\end{tabular}

patients with chronic heart failure remains to be standardised.

Endurance training in chronic heart failure patients has been shown to induce favourable shifts in sympathovagal balance, but whether this is an important mechanism in the improvement of exercise tolerance and prognosis remains to be evaluated.

\section{ARRHYTHMIAS}

Ventricular arrhythmias are common in heart failure and are associated with impaired left ventricular function and a high mortality rate.

In a controlled trial of endurance training in chronic heart failure by Coats et al, ${ }^{12} 24$ hour Holter monitoring showed a significant excess of ventricular ectopic beats (presumed to be related to the unmasking of ventricular automaticity by the slower heart rate). There was, however, no significant change in the rate of potentially arrhythmogenic early premature ventricular beats.

In summary, none of the studies on this subject published to date reports serious ventricular arrhythmias during exercise training.

\section{PERIPHERAL CIRCULATION}

Increased sympathetic tone and stimulation of the renin-angiotensin-aldosterone (RAA) system resulting in a redistribution of regional blood flow-that is, a reduction in maximum muscle blood flow-and abnormalities of vascular control have been reported in chronic heart failure. ${ }^{21}$ The role of the endothelium in coordinating tissue perfusion has been recognised $^{22}$ and endothelial dysfunction of large conduit and small resistance vessels has been documented. ${ }^{23} 26$

Neither Sullivan et $a l^{5}$ nor Coats et $a l^{12}$ observed any change in resting leg blood flow, arteriovenous $\mathrm{O}_{2}$ difference, oxygen delivery, or vascular resistance after endurance training. At peak exercise, however, increases were seen in

Table 5 Effects of exercise training

\begin{tabular}{|c|c|c|c|}
\hline & Exercise time & Peak workload & Peak $\dot{V}_{\mathrm{O}_{2}}, \mathrm{ml} / \mathrm{kg} / \mathrm{min}$ \\
\hline $\begin{array}{l}\text { Uncontrolled } \\
\text { Sullivan }^{5}\end{array}$ & $9.7 \rightarrow 11.5 \mathrm{~min}$ & $520 \rightarrow 613 \mathrm{kpm} / \mathrm{min}$ & $16.8 \rightarrow 20.6$ \\
\hline $\begin{array}{l}\text { Controlled } \\
\text { Coats }^{1112}\end{array}$ & $\begin{array}{l}14.2 \rightarrow 16.8 \mathrm{~min} \\
10.7 \rightarrow 12.3 \mathrm{~min}\end{array}$ & & $\begin{array}{l}14.3 \rightarrow 16.7 \\
13.2 \rightarrow 15.6\end{array}$ \\
\hline $\begin{array}{l}\text { Meyer }^{10} \\
\text {-After training } \\
\text {-After training + } \\
\quad \text { lisinopril }\end{array}$ & $\begin{array}{l}13.5 \rightarrow 15.0 \mathrm{~min} \\
13.6 \rightarrow 16.2 \mathrm{~min}\end{array}$ & & $\begin{array}{l}13.0 \rightarrow 14.6 \\
13.0 \rightarrow 15.9\end{array}$ \\
\hline Davey $^{13}$ & $14.0 \rightarrow 16.0 \mathrm{~min}$ & $96.0 \rightarrow 112 \mathrm{~W}$ & $14.1 \rightarrow 15.4$ \\
\hline Belardinelli ${ }^{16 \star}$ & & $109 \rightarrow 125 \mathrm{~W}$ & $16.6 \rightarrow 19.1$ \\
\hline
\end{tabular}

${ }^{\star}$ Only in patients with abnormal relaxation diastolic filling pattern, type $\mathrm{c}, \mathrm{n}=12$. leg blood flow, arteriovenous $\mathrm{O}_{2}$ difference, and oxygen delivery, due to a decrease in leg vascular resistance.

In a recent study, Hornig et $a l^{8}$ showed that impaired flow dependent vasodilatation in patients with chronic heart failure was restored by local strength training, most probably as a result of increased endothelial release of nitric oxide. Short term treatment with ACE inhibitors does not affect blood flow to the exercising muscle. However, peripheral flow and metabolism may be improved by long term ACE inhibition, resulting in increased exercise performance. ${ }^{26}$ This effect emerges gradually over time and may create the conditions under which working muscle can reverse the intrinsic abnormalities. Furthermore, impairment of peripheral vascular dilatation in response to vasodilator stimuli, resulting in reduced muscle blood flow during exercise, is reversed by physical training. ${ }^{8}$

In summary, various forms of physical training may result in an increased skeletal flow during exercise, resulting in an improved exercise capacity.

SKELETAL MUSCLE

In a substantial proportion of patients with chronic heart failure exertional fatigue is associated with skeletal muscle dysfunction. ${ }^{27}$ Structural and functional changes observed in skeletal muscle are considered major factors that reduce strength, limit endurance exercise capacity, and lead to the early onset of fatigue. ${ }^{28}$ Among the morphological changes observed are a reduction in muscle mass, a shift in muscle fibre type with predominantly oxidative potential (types I and IIA) to fibres with anaerobic capacity (type IIB), and a reduction in mitochondrial size and number. ${ }^{29}$

Alterations in skeletal muscle metabolism are characterised by a reduction in oxidative capacity, resulting in a earlier onset of less efficient anaerobic pathways. ${ }^{30}$ Other mechanisms that may play a role in the reduction of functional capacity of skeletal muscle are a decrease in anabolic functions (changes in insulin resistance and lipid metabolism) and an activation of catabolic factors (cytokine production) resulting in severe muscle wasting. ${ }^{31}{ }^{32}$

The changes in peripheral factors are not specific for patients with chronic heart failure, but have been observed in individuals with restricted physical activity and after bed rest, ${ }^{33} 34$ indicating the importance of physical deconditioning in the limitation of physical activity.

Training related changes in skeletal muscle in chronic heart failure patients have been shown after endurance and local strength training. ${ }^{6}{ }^{9} 9^{15}{ }^{17}{ }^{35-37}$ In general, both endurance and (local) resistance training improve strength and oxidative capacity of skeletal muscle without altering cardiac performance. ${ }^{9} 3637$

Recently Andrews et $a l^{28}$ compared exercise related adaptations in muscle metabolism between patients in NYHA grade II and grade III and observed that the degree of abnormality was related to the symptomatic status of the patient. Anker et $a l^{32}$ showed that predictors of 
exercise capacity and consequently of trainability change with the development of cardiac cachexia. Both these observations underscore the importance of patient selection in the evaluation of effectiveness of certain training regimens. Skeletal muscle function seems to be one of the crucial end points in the evaluation of physical conditioning.

\section{RESPIRATORY FUNCTION}

Pulmonary factors that are important determinants of exercise intolerance in chronic heart failure include pulmonary haemodynamics (affected by chronic pulmonary oedema), airway function, diffusion abnormalities, bronchial hyperresponsiveness, respiratory muscle strength, and ventilation-perfusion inequality. ${ }^{12}$ Exercise hyperpnoea is a common phenomenon in chronic heart failure, occurring at onset of exercise without evidence of arterial hypoxaemia or altered $\mathrm{CO}_{2}$ tension. ${ }^{38}$ Factors stimulating this excessive ventilation response are complex, and include various chemoreceptors $\left(\mathrm{K}^{+}, \mathrm{CO}_{2}, \mathrm{pH}\right.$, lactate, adenosine) and respiratory and skeletal muscle afferents. Stimulation of skeletal muscle ergoreceptors induces generalised vasoconstriction and increases ventilation in chronic heart failure and may therefore form a direct link between metabolic and ventilatory abnormalities. ${ }^{17} \mathrm{~A}$ recent study by Piepoli et al reported a reduction in the enhanced ergoreflex response during exercise in chronic heart failure patients following a six week local strength training programme. ${ }^{17}$

Changes in $\dot{\mathrm{V} C O}{ }_{2}$ equivalent $\left(\dot{\mathrm{V}} \mathrm{E} / \dot{\mathrm{V}} \mathrm{CO}_{2}\right)$ during exercise have been shown to parallel the severity of chronic heart failure. ${ }^{12}$ Dyspnoea during exercise is poorly related to central haemodynamic variables in chronic heart failure, but the enhanced ventilatory response correlates well with the decrease in exercise capacity.

Coats $e t a l^{12}$ found a significant reduction of ventilation after endurance training in chronic heart failure, while Meyer et $a l^{10}$ showed a reduction in minute ventilation at submaximal exercise following endurance training. A decrease in $\mathrm{CO}_{2}$ and lactate production, respiratory exchange ratio, and minute ventilation at submaximal exercise level after training has been reported by Sullivan et al and by Davey and coworkers. ${ }^{13} 19$ These findings are suggestive of a greater expiratory reserve during exercise and may explain the reduced sensation of breathlessness observed after training. Whether this beneficial effect on ventilation reflects more efficient muscular performance, reduced capillary wedge pressures, or an improved matching of ventilation to perfusion in the lung is still not certain. The improved respiratory muscle performance referred to above was also reflected by improved respiratory variables. ${ }^{7}$ All these findings may provide an insight into the poorly understood mechanism of excessive ventilation in chronic heart failure.

EXERCISE TOLERANCE

Exercise time, peak workload, and peak $\dot{\mathrm{V}}_{2}$ are considered to be variables that reflect exercise tolerance and usually improve after training (table 5)..$^{10-13} 16$ Sullivan and coworkers ${ }^{519}$ showed an increase in lactate anaerobic threshold at submaximal exercise performance at a significantly increased $\dot{\mathrm{V}}_{2}$.

The diversity of training intensity, mode, and duration of the local strength training programmes hampers comparisons of the studies; however, both strength and endurance were increased after training. Various forms of physical conditioning can improve peak $\dot{\mathrm{V}}_{2}$, exercise time, and peak workload, and delay anaerobic threshold at submaximal exercise.

SYMPTOMS AND QUALITY OF LIFE

The severity of chronic heart failure is usually assessed by the New York Heart Association classification, which is a subjective appraisal of physical activity. In chronic heart failure trials measurement of quality of life should accompany measures of haemodynamic variables and exercise capacity.

Sullivan et al observed a significant improvement in NYHA functional class from 2.4 to 1.3 in chronic heart failure patients after a training programme of four to six months. ${ }^{5}$ After an eight week home based training programme reported by Coats et al, ${ }^{12}$ symptom assessment was obtained using a modified Likert symptom questionnaire (a self rating scale) of breathlessness, fatigue, chest pain, and daily activities. Improvement in quality of life indices was associated with improvement in exercise performance. ${ }^{11}{ }^{12}$ In the gentle strength training programme by Koch et al, ${ }^{14}$ quality of life was determined as a percentage on a visual scale (of overall improvement as estimated by the patient). The quality of life index increased significantly after training.

It is apparent that quality of life was generally seen to improve in this particular patient group as a result of training, regardless of the method used for evaluation.

\section{Discussion and recommendations}

Not long ago chronic heart failure patients were advised to refrain from physical exertion. More recently it has been shown that selected patients with compensated stable chronic heart failure can safely follow a training programme, thereby improving exercise tolerance and functional status.

Beneficial effects can be observed on cardiac function, peripheral circulation, pulmonary abnormalities, and particularly skeletal muscle. This diversity in the mechanism of improvement can be attributed to the heterogeneity of the chronic heart failure population in relation to cause, pathophysiological mechanism, duration of heart failure, mechanism of compensation, drug treatment regimen, skeletal muscle status, motivation, and type of training programme.

The observed improvements are sometimes small, but may have a major impact on quality of life in heart failure patients. The difference after training is reflected in the patient's ability to cope with the physical demands of day to day activity, thus preventing the need for 
Table 6 Absolute contraindications to exercise therapy

Manifest circulatory insufficiency ("congestive heart failure") Acute myocardial infarction, at least during the first days

Rapidly increasing or unstable angina pectoris

Dissecting aortic aneurysm

Ventricular tachycardia and other uncontrolled dangerous

arrhythmias (multifocal ventricular activity)

Severe aortic stenosis

Recent embolisation, systemic or pulmonary

Active or recent thrombophlebitis

Acute infectious diseases

Diastolic pressure $>115 \mathrm{~mm} \mathrm{Hg}$

Active myocarditis

continuous bed rest and the loss of independence which often results in the need for chronic care. ${ }^{3}$

Most studies to date have examined the effect of aerobic exercise training, a form of endurance training which does not specifically improve muscle strength. Many activities in daily life are, however, of an intermittent nature and require muscle strength as well. In patients with chronic heart failure strength training may increase blood pressure by increasing systemic vascular resistance, with variable increases in left ventricular filling pressure. This may be deleterious but it can be avoided by restricting the muscle mass engaged in the exercise training. The muscle groups should not be engaged in the training simultaneously, but consecutively. These local strength training programmes can increase strength at an exercise level that results in only modest demands on the cardiovascular system. A training programme involving brief and intense work stimuli, ${ }^{9}$ or interval exercise training, ${ }^{18}$ might also be beneficial.

Peak $\dot{\mathrm{VO}}_{2}$ and exercise time are usually used as end points in the evaluation of exercise performance. It is not certain that cardiopulmonary exercise test indices determined at peak exercise represent symptoms observed during daily activities. Therefore other test variables such as the $\dot{\mathrm{V}} / \dot{\mathrm{V}}_{\mathrm{CO}}$ slope and data observed on performance of submaximal exercise might be more closely related to daily activities and quality of life. In addition to cardiopulmonary exercise testing, assessment of quality of life is necessary to establish the effects of the various training regimens. The correct choice of quality of life index has yet to be made and this requires further study.

Contraindications for chronic heart failure patients participating in such a programme (table 6) are the same as for patients with coronary artery disease. ${ }^{2}$ While observing these contraindications, the studies reviewed showed no major complications during or shortly after exercise.

The rate of hospital admission for chronic heart failure is high and both low peak $\dot{\mathrm{V}}_{2}$ and poor exercise capacity are independent risk factors for high morbidity. The favourable effects of training on these two variables might improve the prognosis of heart failure. In reported study periods ranging from six weeks to one year, however, no effect of exercise training on morbidity has been demonstrated, though the numbers are too small to be conclusive. As yet, no data are available on longer term follow up. The time has come to abandon rest as the cornerstone in the treatment of chronic heart failure. There is ample evidence that systematic training is of benefit to these patients. The positive effect of physical training results mainly from improvement in skeletal muscle abnormalities and peripheral vasomotor control, with little or no effect on central haemodynamic function.

Further research is necessary to confirm the role of exercise training as a treatment for patients with chronic heart failure, and to determine the most appropriate intensity, mode, and duration of training. Training can comprise overall endurance training monitored by heart rate, interval training based on percentage of maximum exercise level, or strength training. Muscle groups can be trained simultaneously or consecutively (local training). For training to be effective, the intensity should be sufficiently high, and the frequency should be at least three times a week. Initial training, lasting for at least six weeks, should be followed by a maintenance training regimen, since all improvements are reversible. An active lifestyle should be promoted.

There will probably never be a "standard training programme" for the patient with chronic heart failure. Before such patients can participate in a training programme, it is important to clarify the pathophysiology of their heart failure and thus identify their limiting factors. Finally the patient's individual profile requires definition: the training programme must be tailored to the patient's specific limitations and desired level of activity.

1 Smith TW, Braunwald E, Kelly RA. The management of heart failure. In: Braunwald E, ed. Heart disease. Philadelphia: WB Saunders, 1988:485-543.

2 Kellerman JJ, Shemesh J, Ben-Ari E. Contra-indications to physical training in patients with impaired ventricular function. Eur Heart $\mathcal{F}$ 1988;9(suppl F): 71-7.

3 Kass Wenger N. Left ventricular dysfunction. Exercise capacity and activity recommendations. Eur Heart 7 1988; 9(suppl F):63-6.

4 Dunselman PHJM, Kuntze CEE, van Bruggen A, Beekhuis H, Piers B, Scaf AHJ, et al. Value of New York Heart Association classification, radionuclide ventriculography and cardiopulmonary exercise tests for selection of patients for congestive heart failure studies. Am Heart $\mathcal{F} 1988 ; 116$ : for congestiv $1475-82$.

5 Sullivan MJ, Higginbotham MB, Cobb FR. Exercise raining in patients with severe left ventricular dysfunction. Circulation 1988;78:506-15.

6 Minotti JR, Johnson EC, Hudson TL, Zuroske G, Murata $\mathrm{G}$, Fukushima E, et al. Skeletal muscle response to exercise training in congestive heart failure. F Clin Invest 1990;86: $751-8$.

7 Mancini DM, Henson D, La Manca J, Donchez L, Levine S. Benefit of selective respiratory muscle training on exercise capacity in patients with chronic congestive heart failure. Circulation 1995;91:320-9.

8 Hornig B, Maier V, Drexler H. Physical training improves endothelial function in patients with chronic heart failure. Circulation 1996;93:210-14.

9 Magnusson G, Gordon A, Kaijer J, Sylvén C, Isberg B, Karpakka $\mathrm{J}$, et al. High intensity knee extensor training in patients with chronic heart failure. Major skeletal muscle improvement. Eur Heart f 1996;17:1048-55.

10 Meyer TE, Casadei B, Coats AJS, Davey PP, Adamopoulos $\mathrm{S}$, Radaelli A, et al. Angiotensin-converting enzyme inhibition and physical training in heart failure. $\mathcal{F}$ Intern Med 1991;230:407-13.

11 Coats AJS, Adamopoulos S, Meyer TE, Conway J, Sleight P. Effects of physical training in chronic heart failure. Lancet 1990;335:63-6.

12 Coats AJS, Adamopoulos S, Radaelli A, McCanca A, Meyer TE, Bernardi L, et al. Controlled trial of physical training in chronic heart failure. Circulation 1992;85:2119-31.

13 Davey P, Meyer T, Coats A, Adamopoulos S, Casadei B, Conway J, et al. Ventilation in chronic heart failure: effects of physical training. Br Heart f 1992;68:473-7.

14 Koch M, Douard H, Broustet JP. The benefit of graded physical exercise in chronic heart failure. Chest 1992; 101(suppl 5):231-5S. 
15 Adamopoulos S, Coats AJS, Brunotte F, Arnolda L, Meyer $\mathrm{TH}$, Thompson $\mathrm{CH}$, et al. Physical training improves skeletal muscle metabolism in patients with congestive hear failure. F Am Coll Cardiol 1993;21:1101-6.

16 Belardinelli R, Georgiou D, Cianci G, Berman N, Ginzton L, Purcaro A. Exercise training improves left ventricular diastolic filling in patients with delated cardiomyopathy. Circulation 1995;91:2775-84.

17 Piepoli M, Clark AL, Volterani M, Adamopoulos S, Sleight $\mathrm{P}$, Coats AJS. Contribution of muscle afferents to the haemodynamic, autonomic and ventilatory responses to exercise in patients with chronic heart failure. Circulation 1996;93:940-52.

18 Meyer D, Samek I, Schwaibold M, Westbrook S, Hajric R, Lehmann $M$, et al. Physical responses to different modes of interval exercise in patients with chronic heart failureapplication to exercise training. Eur Heart F 1996;17:10407 .

19 Sullivan MJ, Higginbotham MB, Cobb FR. Exercise training in patients with chronic heart failure delays venti-
latory anaerobic threshold and improves submaximal exerlatory anaerobic threshold and improves subm
cise performance. Circulation 1989;79:324-9.

20 Wilson JR, Rayos G, Yeoh TK, Gothard P, Bak K. DissociaWilson JR, Rayos G, Yeoh TK, Gothard P, Bak K. Dissociation between exertional symptoms and circulatory function

21 Cohen-Solal A Improving exercise tolerance in patients Cohen-Solal A. Improving exercise tolerance in patients
with chronic heart failure: should we treat the heart or the periphery? Eur Heart f 1989;10:866-71.

22 Henderson AH. Endothelium in control (St Cyres lecture) Br Heart f 1991;65:116-25.

23 Drexler H, Hayoz D, Munzel T, Hornig B, Just H, Brunner $\mathrm{HR}$, et al. Endothelial function in chronic congestive heart failure. Am f Cardiol 1992;69:1596-601.

24 Hayoz D, Drexler H, Munzel T, Hornig B, Zeiher A, Just H, et al. Flow-mediated arteriolar dilation is abnormal in con-

25 Kubo SH, Rector TS, Bank AJ, Williams RE, Heifetz SM. Endothelium-dependent vasodilation is attenuated in Endothelium-dependent vasodilation is attenuated in
patients with heart failure. Circulation 1991;84:1589-96.

26 Datients with heart failure. Circulation 1991;84:1589-96. Lehmann M, Just H. Contrasting peripheral short-term and long-term effects of converting enzyme-inhibition in patients with congestive heart failure: a double blind, placebo-controlled trial. Circulation 1989;79:491-502.

27 Drexler H. Skeletal muscle failure in heart failure. Circulation 1992;85:1621-3.
28 Andrews R, Walsh JT, Evans A, Curtis S, Cowley AJ. Abnormalities of skeletal muscle metabolism in patients with chronic heart failure: evidence that they are present at rest. Heart 1997;77:159-63.

29 Wilson JR, Martin JL, Schwartz D, Ferraro N. Exercise intolerance in patients with chronic heart failure: role of impaired nutriti

30 Kemp GJ, Thompson CH, Stratton JR, Brunotte F, Conway $\mathrm{M}$, Adamopoulos S, et al. Abnormalities in exercising skeletal muscle in congestive heart failure can be explained in terms of decreased mitochondrial ATP synthesis, reduced metabolic efficiency, and increased glycogenolysis. Heart 1996;76:35-41.

31 Lipkin DP, Jones DA, Round JM, Poole-Wilson PA. Abnormalities of skeletal muscle in patients with chronic heart failure. Int $\mathcal{F}$ Cardiol 1988;18:187-95.

32 Anker SD, Swan JW, Volterrani M, Chua TP, Clark AL, Poole-Wilson PA, et al. The influence of muscle mass, strength, fatigability and blood flow on exercise capacity in cachectic and non-cachectic patients with chronic heart failure. Eur Heart F 1997;18:259-69.

33 Chatic Z, Zannad F, Jcandel C, Lherbier B, Escanye J-M, Robert J, et al. Physical deconditioning may be a mechanism for the skeletal muscle energy phosphate metabolism abnormalities in chronic heart failure. $\mathrm{Am}$ Heart F 1996;131:560-6.

34 Convertino VA, Bloomfield SA, Greenleaf JE. An overview of the issues; physiological effects of bedrest and restricted physical activity. Med Sci Sports Exerc 1997;29:187-90.

35 Drexler H, Riede U, Münzal T, König H, Funke E, Just H. Alterations of skeletal muscle in chronic heart failure. Circulation 1992;85:1751-9.

36 Hanson P. Exercise testing and training in patients with chronic heart failure. Med Sci Sports Exerc 1994;26:527-37.

37 McKelvie RS, Teo KK, McCartney N, Homen D, Montague T. Yunuf S. Effects of exercise training in patients with congestive heart failure. $\mathcal{F} \mathrm{Am}$ Coll Cardiol 1995;25:789-96.

38 Sullivan MJ, Higginbotham MB, Cobb FR. Increased exercise ventilation in patients with chronic heart failure: intact ventilatory control despite hemodynamic and pulmonary abnormalities. Circulation 1988;77:552-9. 